\title{
Comunidad y gobierno local en el escenario global
}

Adolfo Rodríguez Bernal 



\section{Comunidad y gobierno local en el escenario global*}

Adolfo Rodríguez Bernal**

Recibido: Septiembre 2006

Aceptado: Octubre 2006
* Dilema producción-mercado

** Profesor titular ESAP

Estudios: Sociólogo Universidad Nacional de Colombia; Abogado Universidad Libre de Colombia; DEA (equivalente Magíster) en Política Pública y Descentralización Universidad de la Sorbona, Paris III. Cargos: Profesor Titular de la ESAP; Ex-Rector Universidad Pedagógica Nacional, UPN; Ex-Director de los Posgrados de la ESAP; Ex-Asesor del Ministro de Salud; Ex-Asesor de Miembro de la Asamblea Nacional Constituyente; Consultor PNUD-Ministerio de Salud; Consultor DNP-FONADE; Profesor Universitario: Universidad Nacional, Distrital, Andes, Externado, Libre. Publicaciones y Trabajos de Investigación: Cultura Universitaria y Cambio Social, 2002; La Moderna Noción de lo Público, 2000; Política y Gerencia Pública en Colombia; Polítique Pu- 


\title{
COMUNIDAD Y GOBIERNO LOCAL EN EL ESCENARIO GLOBAL
}

\author{
Adolfo Rodríguez Bernal
}

\section{RESUMEN:}

La ponencia plantea la necesidad de asumir un compromiso intelectual para la construcción colectiva de directrices sociales en una perspectiva metodológica, inductiva y analítica, que involucre problemas propios de la vida local (desarrollo económico restringido por cesión del mercado local a las transnacionales, inseguridad alimentaria que afecta la reproducción de la fuerza de trabajo y ausencia de democracia participativa) y señale actores y contradicciones.

En este contexto, se analizan mediaciones y estrategias de acción gubernamental en las instancias local, regional y nacional, tendientes a la satisfacción de necesidades y a la solución de dificultades, injusticias y conflictos. Si estos problemas no son resueltos se convierten en situaciones de ingobernabilidad, ilegitimidad y autoritarismo, las que a su vez generan reacciones y respuestas ciudadanas y colectivas expresas en la movilización social.

Los cambios inducidos por la acumulación capitalista global, bajo la orientación del modelo de mercado, han conferido primacía a la política económica financiera sobre la comercial y productiva, lo que sustenta a un gobierno mundial que no tiene capacidad para evitar la reproducción de los problemas de la globalización de la riqueza y de la localización de la pobreza, causantes de conflictos, guerras y de vastos movimientos antiglobalización.

\section{ABSTRACT:}

The proposal raises the necessity to assume an intellectual commitment for the collective building of social directives in methodological, inductive and analytical perspective, that involves characteristic problems of the local life (economic development restricted by cession of the local market to the transnational companies; nourishing insecurity that affects the labor force reproduction and absence of democratic participation) and indicates the actors and contradictions.

In this context, mediations are analyzed as well as government action strategies in the local, regional and national instances, tending to the satisfaction of needs and the solution of difficulties, injustices and conflicts. If these problems are not solved they become situations of ungovernability, illegitimacy and authoritarianism, which, on their side, generate citizen and collective reactions and answers expressed in the social mobilization.

The changes induced by the global capitalist accumulation, under the direction of the market model, have conferred primacy to the financial economic policy over the commercial and productive one, which sustains a world-wide government that doesn't have the capacity to avoid the reproduction of the problems about the globalization of wealth and the localization of poverty, which are the causes of conflicts, wars and vast anti-globalization movements.

\section{Resúmenes \& abstracts}




\section{PALABRAS CLAVE:}

Gobierno local, inseguridad alimentaria, democracia participativa, globalización.

\section{KEY WORDS:}

Local governments, nourishing insecurity, participation democracy, globalization. 
En el contexto del modelo global del mercado capitalista se produce el encadenamiento en los escenarios territorial, nacional y global, de tres fenómenos complejos: problemas de las comunidades locales ligados a problemas políticos nacionales y mundiales; articulación de capacidades de gobernabilidad; y, de acciones de participación en movimientos locales, nacionales y globales. El escrito tiene tres partes:

En la primera, se muestra como ante la incapacidad de los gobiernos locales para satisfacer necesidades y de dar solución a los problemas de la vida local en los campos del desarrollo económico, de la seguridad alimentaria y de la inequidad social, se engendran acciones colectivas, que sirven de soporte al surgimiento de movimientos sociales propositivos que buscan la resolución de conflictos, injusticias, desigualdades y situaciones de exclusión social.

En la base de los conflictos entre estos dos agentes del desarrollo local, se encuentra la discusión sobre las autonomías locales, principalmente, entre las autonomías territoriales que confieren competencias a los gobiernos locales y las autonomías comunitarias base de toda acción colectiva y, en especial, de los movimientos sociales.
En la segunda, se analizan mediaciones y estrategias de acción gubernamental local y nacional, tendientes a la satisfacción de necesidades y a la solución de problemas, injusticias y conflictos. Se pone en evidencia el bajo grado de gobernabilidad, debido a la ausencia de consistentes estrategias de descentralización y al creciente poder de los movimientos sociales en regiones y localidades.

Los gobiernos locales y regionales muestran incapacidad para proveer soluciones a dicha problemática, razón por la cual, esta es trasladada al gobierno central quién también actúa con improvisación, como 'apaga incendios'. Esta situación genera nuevos problemas políticos de ingobernabilidad, ilegitimidad, autoritarismo y reacciones ciudadanas y colectivas que cobran expresión en la movilización social.

En la tercera, los cambios inducidos por la acumulación capitalista global, bajo la orientación del modelo de mercado, han conferido primacía a la política económica financiera sobre la comercial y productiva, lo que demanda mediación del gobierno nacional en la adopción de políticas económicas y sociales y en la generación de reformas políticas y de gestión. No obstante, ni el gobierno mundial ni el nacional han

blique et Decentralisation en Colombie; El Diseño de la Investigación. Seminarios y Eventos: Encuentro de Rectores de la Unión Europea y de América Latina; Conferencia Regional sobre Educación Superior en América Latina; Seminarios Nacionales e Internacionales en Política y Administración Pública. Asociaciones: PLURAL: Corporación Centro de Estudios Constitucionales, PARCOMUN: Fundación para la Participación Comunitaria. 
mostrado capacidad de acción tendiente a solucionar los, cada vez más polarizados, problemas de globalización de la riqueza y localización de la pobreza, causantes de conflictos, guerras y movimientos antiglobalización. Basta con observar, las metas de reducción de la pobreza en el mundo a la mitad, antes de 2015, propuesta por Naciones Unidas en la Cumbre del Milenio, para comprender la dimensión de este insoluble problema.

La ponencia plantea la necesidad de asumir un compromiso intelectual para la construcción colectiva de directrices sociales en una perspectiva metodológica, inductiva y analítica, que de prioridad a problemas propios de la vida local (atraso económico por cesión del mercado local a las transnacionales, inseguridad alimentaria que afecta la reproducción de la fuerza de trabajo y ausencia de democracia participativa), señalando el papel jugado por los actores, los intereses y sus contradicciones. Con estos fundamentos enraizados en la realidad social, comprender como se generan los complejos problemas de gobernabilidad nacional y global y las alternativas de solución forjadas por fuerzas sociales, acciones colectivas y movimientos sociales.

\section{Vida Local, Problemas, Autonomías y Acciones Colectivas}

"Las necesidades y problemas de la vida local que se expresan en atraso económico, inseguridad alimentaria y falta de participación, engendran acciones colectivas y movimientos sociales que buscan justicia, igualdad e inclusión social"

En el marco de la vida local, los individuos y comunidades, satisfacen las necesidades esenciales de su existencia en la producción, el comercio y el consumo; reproducen su fuerza de trabajo con empleo, educación, y salud; participan activamente de la vida pública local con acciones de defensa de la ecología y del medio ambiente.

La economía local se ocupa de la producción de la existencia del individuo y de las comunidades, propiciando formas de organización de la producción material, del comercio, de la distribución y del consumo de bienes y prestación de servicios.

La reproducción de la fuerza individual y colectiva se logra mediante la Seguridad Alimentaria, como derecho humano básico; indispensable para el desarrollo sustentable; este derecho implica no solo aspectos materiales de cantidad y calidad sino aspectos culturales relacionados con la alimentación; las formas justas y democráticas de propiedad, uso y acceso a la tierra son esenciales para crear sistemas alimenticios sostenibles; agricultura sustentable y biodiversidad que conservan la base de los recursos indispensables; iniciativas populares en el área de reforma agraria, organización comunitaria; papel primordial de la mujer en la producción de alimentos y su almacenamiento; ecología, aspectos sociales y económicos que permiten agricultura sostenible; adecuada política 
de seguridad alimentaria; distancia mínima entre productores y consumidores; atención a grupos vulnerables; oportunidades de intercambio; beneficios por la práctica agrícola ${ }^{1}$

El normal desarrollo de estas actividades demanda de la participación activa de los ciudadanos y comunidades en la vida pública local en la toma de decisiones democráticas con acciones específicas de defensa de la ecología y del medio ambiente.

\section{Problemas Locales}

La vida local en la globalización presenta tres problemas centrales: cesión del mercado a las empresas transnacionales, afectando la producción de su existencia; inseguridad alimentaria que limita la reproducción de las fuerzas de trabajo; $y$, carencia de representación adecuada para hacer efectiva la participación en la vida pública local.

Primero, el dominio del mercado mundial en las localidades limita severamente la producción de bienes y servicios y por tanto, las colectividades territoriales se ven precisadas a vincularse al mercado de bienes y servicios y a la prestación de servicios públicos, generando desempleo, informalidad y marginando su accionar creativo.

Segundo, la seguridad alimentaria está en crisis a nivel mundial, espe- cialmente en los países del tercer mundo, por una serie de causas o por varias de ellas a la vez. Entre otras: la injusta distribución de la tierra, el agotamiento de los recursos productivos de suelo y agua. Las catástrofes climáticas y las plagas; la degradación ambiental producto de la sobreexplotación de suelos, los cambios climáticos, la salinización de los suelos, la erosión, el uso de tecnologías contaminantes; catástrofes sociales que desarticulan la organización política y productiva; políticas de producción que privilegian el consumo externo; insuficiencia y defectos en los sistemas de distribución de alimentos; modelos económicos y planes nacionales que postergan el desarrollo, la sustentabilidad y la importancia de la agricultura ${ }^{2}$.

Tercero, la crisis de la democracia representativa, ha implicado pérdida de soberanía ciudadana, problemas prebendatarios y de financiación de las campañas políticas y del sistema electoral, clientelización de los partidos $\mathrm{y}$ pérdida de capacidad de decisión del parlamento.

Tesis 1: "Los problemas de la vida local en el marco del modelo de mercado global, demandan cambios y soluciones alternativas que se hacen más complejas, porque el país sigue atado a los patrones de comportamiento exigidos por la estructura local tradicional".

Cfr. Foro Global de ONGS de Río de Janeiro de 1992.

Secretaria de Agricultura y Pesca del Valle del Cauca. 


\section{Autonomías territoriales y \\ Comunitarias.}

En segundo lugar, la resolución de conflictos invoca, de un lado, las autonomías territoriales, sujetas a sus respectivas jurisdicciones espaciales, locales, regionales, nacionales; $\mathrm{y}$, de otro, las autonomías comunitarias que tienen la capacidad de trascender otras instancias territoriales. La invocación de uno u otro tipo de autonomía plantea distintas visiones de los actores en orden a la resolución de problemas y conflictos en el seno de la comunidad local, poniendo, en contraste, planteamientos gubernamentales y la visión de la comunidad.

Autonomía Territorial. En la perspectiva de la regulación, el gobierno local ha de facilitar la expansión del mercado, reconociendo su predominio sobre la producción y el desarrollo social. Debe equilibrar la competitividad y la productividad con adecuado uso de los recursos naturales y del medio ambiente y conlleva su coparticipación en la regulación de la reproducción social, la seguridad y prestación de servicios públicos. Según la carta política las autonomías territoriales tienen instancias que se complementan o actúan de manera subsidiaria.

Las entidades territoriales gozan de autonomía para la gestión de sus intereses, dentro de los límites de la constitución y de la ley. En tal virtud tendrán los siguientes derechos: gobernarse por autoridades propias; ejercer las competencias que le correspondan; administrar los recursos y establecer los tributos necesarios para el cumplimiento de sus funciones y participar en las rentas nacionales (Artículo 287 Constitución Nacional).

Autonomías Departamentales. Los departamentos tienen autonomía para la administración de los asuntos seccionales y la planificación y promoción del desarrollo económico y social dentro de su territorio en los términos establecidos por la constitución. Los departamentos ejercen funciones administrativas, coordinación y complementaridad de la acción municipal, de intermediación entre la nación y los municipios y de prestación de los servicios que determinen la constitución y las leyes. Estas autonomías tienen un ámbito de acción más amplio que las municipales y se concretan en estas facultades:

A nivel económico: regular el uso, preservación, aprovechamiento, control y defensa de su territorio, recursos naturales y medio ambiente, en coordinación con las comunidades y municipios de la región; planear y ejecutar programas de desarrollo regional. En todo caso, tener una participación directa en los planes que el departamento y el estado tengan para la región; negociar y recibir recursos económicos del departamento y del estado central y distribuirlos, en forma proporcional, en su ámbito territorial. En su caso, instituir impuestos que permitan recaudar fondos propios para su región; administrar los posibles fondos de compensación y desarrollo que llegara a instituir el estado para mitigar los desequilibrios económicos de las regiones respecto del resto de la na- 
ción; proporcionar apoyo administrativo y técnico para el desarrollo de su región en los niveles económico, político y cultural.

En el terreno político: operar como instancia superior de coordinación entre las comunidades y municipios, y entre éstos y las instancias nacionales; a través del órgano legislativo, reconocer y emitir normas generales de acuerdo a los principios que sustentan el derecho, con competencia en todo el ámbito regional; disponer de un órgano ejecutivo nombrado con base en los mecanismos propios de elección.

En el campo jurídico: actuar como una segunda instancia en el caso de conflictos que superen el ámbito de una comunidad, o en el supuesto de problemas que las comunidades les sometan voluntariamente debido a su gravedad.

A nivel social: elaborar planes de educación intercultural acordes a la realidad y los intereses de las comunidades, en coordinación con las autoridades educativas estatales y nacionales; velar por que efectivamente se respete la cooficialidad de las lenguas indígenas junto con el español, y potenciar el uso y desarrollo de los idiomas indígenas; proteger y desarrollar los conocimientos y la medicina tradicional de los pueblos; rescatar los conocimientos técnicos e innovativos y promover la construcción de vivienda comunitaria.

Entre las ventajas de implantar autonomías regionales, se ha señalado que manejarían recursos económicos suficientes y que tendrían la capacidad de implementar planes de desarrollo regional. Al mismo tiempo, contarían con un poder político que les permitiría negociar con otras entidades territoriales o estados desde una posición de fuerza notablemente mayor que la de las comunidades y municipios.

Autonomías Municipales. Al municipio como entidad fundamental de la división político-administrativa del Estado, le corresponde prestar los servicios públicos que determine la ley, construir las obras que demande el progreso local, ordenar el desarrollo de su territorio, promover la participación comunitaria, el manejo social y cultural de sus habitantes y cumplir las demás funciones que le asignen la constitución y las leyes (Art. 31).

El desarrollo local es una modalidad que busca responder "desde abajo" a la crisis estructural del ajuste propio del capitalismo tecnológico actual y pretende superar la "crisis de proximidad" producida por la modernización.

En estos términos, el desarrollo endógeno local es una expresión algo tautológica en tanto el desarrollo presupone una autonomía creciente sobre el territorio, una idoneidad creciente para reinvertir el excedente "in situ", una capacidad en aumento para generar conocimiento e innovaciones, y un fortalecimiento de la identidad cultural y el sentido de pertenencia territorial.

Autonomía Comunitaria. La comunidad territorial ha sido desbordada por otras comunidades existentes: 
marginales internas como los indígenas y la población negra, por las comunidades fronterizas y en fin por las comunidades virtuales que emergen en la red de localidades. La comunidad territorial reconoce otras formas de relación de la comunidad más allá de la sociedad civil local y amplía el espectro hacia la ciudadanía nacional y transnacional. La comunidad local y la sociedad real no solo construyen relaciones civiles locales sino una sociedad civil nacional y mundial como marco para sus actuaciones.

Emergen nuevos actores y protagonistas dentro y fuera de la localidad con intereses diversos que deben ser cohesionados por el gobierno local. Los actores desbordan lo territorial, pues, están asentados en el territorio local, son vecinos o están fuera de él pero vinculados por las redes virtuales de desarrollo social. Estos actores son críticos no solo de la gestión local sino de las políticas nacionales y de la esfera internacional. Además, los actores marginados como los indígenas y la población negra adquieren un gran protagonismo generando grandes movimientos de masas.

En síntesis, la autonomía de las comunidades locales va, más allá de las territoriales, y comprende las siguientes facultades:

En el ámbito económico: controlar y gestionar el aprovechamiento de las tierras comunales y recursos naturales de la comunidad; planear y ejecutar proyectos de desarrollo comunitario; recaudar aportes propios y recibir recursos económicos del munici- pio, del departamento o del estado, administrándolos según su criterio.

En el terreno político: elegir y nombrar a las autoridades comunitarias con base en sus mecanismos propios y sin la intromisión de los partidos políticos; tomar en asamblea las decisiones que atañen a la vida pública de la comunidad; participar en la elección de las autoridades del municipio correspondiente y, en su caso, del gobierno regional autónomo. Esto debe incluir tanto la facultad de votar como la de ser votados/as.

En la esfera jurídica: acordar, mantener y modificar las normas sociales y jurídicas que rigen la vida de la comunidad; ejercer plenamente las facultades jurisdiccionales para juzgar las infracciones a dichas normas por medio de sus autoridades tradicionales, siempre que la comunidad manifieste su voluntad de hacerlo, así como ejecutar las resoluciones correspondientes.

En el campo cultura: Protección y desarrollo de su lengua, usos y costumbres; Respeto por sus ritos e instituciones religiosas: decidir libremente la entrada o no de iglesias en la comunidad; practicar sus creencias y ritos religiosos propios sin injerencia de ninguna iglesia.

En el ámbito social: autonomía organizativa y en relación con otras comunidades; en el campo educativo, decidir sobre los planes de enseñanza y selección de programas y maestros que van a intervenir en la comunidad; respeto por el conocimiento y avances de la medicina tradicional; por la protección y conservación del medio 
ambiente; seguridad y vivienda; consideraciones sobre sus progresos en el campo de la tecnología.

Tesis 2: "El problema de la autonomía local está asociada al nivel de desarrollo y a la cuestión de la descentralización (que actualmente no supera el 25\% de los entes locales y solo en lo social) $y$ que despierta sospechas entre el gobierno, limitando las competencias y transferencias hacia las entidades locales".

\section{Acciones Colectivas y Movimiento Social.}

Los actores principales que hacen presencia en la globalización son: el gobierno en todas sus instancias con responsabilidades locales; el sector privado con vínculos nacionales $\mathrm{y}$ mundiales; los ciudadanos y actores sociales tales como comunidades indígenas, población afrodescendiente, mestizos y los grupos armados legales e ilegales.

Esta situación de la vida local sirve de soporte a distintas visiones $y$ dinámicas sobre el desarrollo económico, social y político de las localidades desde las autonomía territoriales y comunales, desde distintos intereses y desde el significado de la acción de los agentes del desarrollo local frente a las alternativas de solución de los problemas, lo que traduce problemas de gobernabilidad de estos territorios.

Las alternativas de solución de los problemas y necesidades de la vida local, de producción, de seguridad alimentaria y de participación social, han generado acciones colectivas, resultado de la combinación de los inte- reses que han sido afectados y buscan su resolución para superar conflictos, injusticias, desigualdades $\mathrm{y}$ exclusiones.

Las acciones colectivas se generan en torno a uno o varios intereses $\mathrm{u}$ objetivos comunes de la vida local del desarrollo económico, de la seguridad alimentaria, o de la participación social, en distintos campos: agrario, urbano, cultural, nacional y global, a partir de articulaciones diferenciadas en torno a sus intereses.

Acciones agrarias tales como: uso, tenencia o control de la tierra, crédito y financiamiento agropecuario, tecnología e innovación, ecología y conservación del medio ambiente. Acciones urbanas: servicios públicos, educación, salud y seguridad, vivienda, impuestos. Acciones culturales, religiosas, de mujeres, de jóvenes, de minorías, ecológicas. Acciones nacionales: frente a la violencia, respeto a los derechos humanos por grupos armados ilegales, fuerza pública. Acciones globales: contra el ALCA, el TLC, respeto al derecho internacional humanitario, protestas antiglobalización, etc.

Las acciones colectivas son variadas y toman diversas formas: debates y mítines, toma de tierras, de carreteras y de vías principales, de instituciones, marchas, congresos, seminarios y eventos, huelgas de hambre, paros cívicos, protestas masivas, etc.

En este contexto se entretejen intereses, objetivos y acciones en torno a visiones, concepciones e ideologías que estructuran un conjunto de acciones colectivas que servirán de funda- 
mento a la consolidación de movimientos sociales futuros. El movimiento social es, entonces, una forma de comportamiento colectivo orientado a enfrentar injusticias, desigualdades y exclusiones, promoviendo o haciendo resistencia al cambio, mediante un conjunto de acciones colectivas.

Al efecto, el movimiento social aparece como una organización estructurada que tiene como fin, objetivos y metas dentro de un marco ideológico claro y orientado al cambio social con propuestas alternativas de solución de los problemas sociales.

El movimiento social se encuentra inmerso en la resolución de conflictos y por tanto, choca de manera permanente con intereses y otros actores: el Estado en la resolución de conflictos, el sector privado, comunidades y grupos de poder territoriales, nacionales o globales.

Tesis 3: "En el ámbito de la globalización, cambia la perspectiva de solución de la problemática local, pues, en la toma de decisiones la primacía corresponde a las autonomías comunitarias sobre las territoriales, motivando acciones colectivas y movimientos sociales".

\section{Gobierno Local, Gobernabilidad y Movimiento Social}

\footnotetext{
"La incapacidad del gobierno local en la resolución de problemas de la vida local, en su función de mediación territorial y de ajuste de la política pública, genera nuevos problemas de ingobernabilidad, ilegitimidad y autori-
}

tarismo que multiplican acciones colectivas y movimientos sociales"

El imperio del mercado cambió radicalmente el panorama del gobierno y de la gestión local. Las entidades locales se convierten en sujetos políticos con autonomía territorial, lo que les permite asumir responsabilidades respecto a la colectividad territorial, al gobierno central y al mundo global. Lo local es el centro de la reorganización geográfica del espacio y no solo sujeto de obligaciones soberanas.

La satisfacción de las necesidades sociales y la resolución de los problemas locales están mediadas por la estructura del poder local, es decir, por visiones, intereses y objetivos de los actores del desarrollo y cambio local. Por tanto, la dinámica local debe ser examinada en dos perspectivas contradictorias: desde la noción de gobernabilidad, como enfoque top-down, desde el gobierno hacia la sociedad civil, observando las autonomías territoriales y el concepto de gobernanza, como perspectiva botoom-up, que desde lo social se dirige hacia la acción gubernamental, analizando la interacción compleja entre los diferentes actores políticos, en particular, del ciudadano y las comunidades que reivindican sus propias autonomías.

\section{Gobierno Local, Mediación, Ajustes y Estrategias de Política}

La gobernabilidad es la capacidad que tienen los gobiernos para satisfacer demandas básicas de la población, 
es decir, implica el establecimiento de un equilibrio dinámico entre el nivel de las demandas sociales y la capacidad de respuesta gubernamental.

Para Juan Rial: "Gobernabilidad es la capacidad de las instituciones y de los movimientos de avanzar hacia objetivos definidos de acuerdo a su propia actividad y de movilizar con coherencia las energías de sus integrantes para proseguir esas metas previamente definidas"3. Para Camou por su parte, gobernabilidad es un estado de equilibrio dinámico entre demandas sociales y capacidad de respuesta gubernamental. Eficacia gubernamental y legitimidad social se combinan positivamente en un círculo virtuoso de gobernabilidad, garantizando la estabilidad de los sistema políticos"4

El enfoque del buen gobierno desde la gobernabilidad neoliberal, demanda examinar la mediación territorial y política del gobierno local así como las estrategias locales adoptadas por ellos para conseguir sus objetivos y metas.

\section{Mediación del Gobierno Local}

Los gobiernos locales, deben asumir compromisos políticos en tres direcciones: primero, con las necesidades de la vida local; segundo, con la nación y la región en la ejecución de políticas sectoriales para la producción, el comercio, las finanzas locales y la conservación del medio ambiente; $\mathrm{y}$, tercero, con los encargos de ejecución de la política social diseñada en el campo internacional y mediadas por el gobierno nacional, asumiendo obligaciones en la política cultural de consumo y de masificación social.

Este conjunto de circunstancias explican la necesidad de implementar profundas reformas políticas para el desarrollo local, iniciadas generalmente desde el gobierno central y para atender los ajustes impuestos por las relaciones internacionales.

El gobierno local despliega un rol mediador en tres grandes espacios: articulación del municipio con otras localidades, el departamento y la región; relaciones de la localidad con el gobierno central y sus vínculos con empresas transnacionales, ETN, y organismos internacionales.

En el primer lugar, le corresponde planear el desarrollo local, cobrar tributos, recibir y aplicar transferencias de recursos nacionales, prestar servicios públicos, construir obras necesarias al desarrollo, ordenar el territorio, promover la participación comunitaria, el manejo social y cultural de sus habitantes, coordinar acciones de cooperación con otras localidades, forjar programas de complementariedad y subsidiariedad con el departamento y la nación, crear programas de co-financiación de proyectos de desarrollo y demás funciones de su competencia.

Citado por Camou, Gobernabilidad y Democracia.

4 Camou, Antonio, Camou, Antonio, Gobernabilidad y Democracia, Cuaderno de Divulgación de a Cultura Democrática, Instituto Federal Electoral. 
En segundo lugar, el gobierno local, ha de asumir compromisos políticos con la nación en la ejecución de políticas sectoriales para la producción, las finanzas locales, el comercio y la conservación del medio ambiente; ejecución de la política social diseñada en escenarios internacionales y mediadas por el gobierno nacional; $y$ asumir la prestación de los servicios públicos.

En tercer lugar, el gobierno local contribuye a la expansión mundial del mercado y el consumo, a través de las ETN, superando la relación ciudadana en la sociedad civil. Con intervención de Organismos Internacionales e Intergubernamentales, busca romper la marginalidad social, intensificando relaciones entre los consumidores, a través de los medios de comunicación; masificación social en torno a valores y criterios de mercado y consumo, promoviendo industrias culturales para el consumo, visibilizando distintas culturas étnicas, religiosas y nacionales, propiciando el auge de las artesanías y el folclor.

La glocalización aparece como una estrategia cultural que busca integrar la localidad al consumo mundial, mantener el monopolio de la información y dentro de una cultura económica glocal, manejar los efectos de movimientos de turistas, inmigrantes, refugiados, exilados, desplazamientos de grupos humanos, trabajadores extranjeros y de las personas y grupos en constante movimiento.

Replantear el desarrollo desigual entre lo local y las demás localidades del mundo, promoviendo relaciones civiles de consumo; buscando la ruptura de los vestigios del colonialismo con la participación local en redes mundiales.

\section{Ajustes a la Política Local}

Como sujeto social, la localidad debe asumir un comportamiento político en el manejo de responsabilidades, competencias, funciones y recursos. Además, por el carácter político de la elección popular de sus autoridades, se produce un proceso de repolitización de lo local, lo que explica el creciente interés de la ciencia política por este fenómeno.

Este conjunto de procesos, exige al gobierno local la realización de un proceso de ajuste permanente de política pública en relación a su ejecución e implementación, a la reforma política y administrativa, acorde al nuevo modelo de gestión.

La gobernabilidad territorial esta ligada a la viabilidad de las políticas públicas y tiene como objetivos la búsqueda de equilibrios en: políticas de desarrollo económico sustentable; coherencia sectorial-territorial; política de bienestar y logro de consensos entre democracia y mercado; política cultural que busca armonizar lo local y lo global, donde ninguno de estos elementos es más importante que los demás, ni pueden perder su identidad y sus objetivos cuando se interrelacionan.

La adopción y ejecución de política local considera tres importantes espa- 
cios: promoción del desarrollo económico local, aumento del bienestar social y desarrollo territorial. Las políticas de promoción del desarrollo local se desdoblan en política de fomento de la productividad-competitividad y de protección del medio ambiente; la política de bienestar social en triple dimensión como política cultural, de empleo y de seguridad social; $y$, la política de desarrollo territorial como política urbana y agraria.

La política de promoción del desarrollo económico local lleva implícita: la superación de problemas económicos propios de relaciones tradicionales que han operado en el campo y la informalidad en la ciudad, con el fin de generalizar el tráfico mercantil; sustituir las relaciones políticas ancestrales como el caciquismo y el compadrazgo por vínculos democráticos; $y$, reemplazar las antiguas relaciones comunales por relaciones civiles de mercado.

La política de bienestar social busca garantizar la reproducción de la fuerza laboral a cargo de un conjunto de agencias oficiales, privadas, con o sin ánimo de lucro. También busca la ruptura de privilegios clientelistas para establecer un sistema social más igualitario; $y$, en fin, el cambio de actitudes y valores paternalistas y autoritarios para edificar una democracia social.

La política de desarrollo territorial busca transformar relaciones sociales tradicionales por las típicas de la sociedad capitalista moderna con la construcción de la sociedad civil más allá de las fronteras nacionales. Pone el acento en la transformación de vín- culos de las comunidades locales por relaciones urbano/rurales modernas, superando formas precaristas e informales para dar paso a la construcción de ciudadanía local; la ampliación del consumo y masificación social.

Estrategias, Centralización. Descentralización y Privatización. El desplazamiento de las hegemonías nacionales por el espectro del mercado, han estado precedidas por tres estrategias que buscan acelerar el tránsito de la situación tradicional hacia el desarrollo local moderno. Estas estrategias de centralización, descentralización y privatización son definidas por las naciones desarrolladas integradas al mercado mundial y mediadas por los gobiernos de países de menor desarrollo.

La excesiva centralización y monopolización de funciones por el Estado central entra en crisis. La descentralización territorial es una estrategia para mejorar la gobernabilidad local o la capacidad para generar "buen gobierno", en términos neoliberales, para atender la complejidad de la vida local y las demandas de los ciudadanos y comunidades locales.

La descentralización territorial crea condiciones para la movilización de los recursos públicos y el acceso a la inversión privada, apertura gradual de mercado, movilidad de mercancías, de la fuerza del trabajo y del desarrollo del turismo. La responsabilidad se descentraliza y el concepto de autonomía local, cambia las relaciones Estado central, empresas y organismos globales.

La estructura jurídica local inmersa en lo nacional debe ajustarse a las de- 
mandas globales, lo que implica asumir responsabilidades locales, superando el tutelaje en la negociación y cooperación, antes ejercido por departamentos y el Estado central.

El énfasis se centra ahora, en la descentralización territorial para asumir sus responsabilidades frente a nuevas competencias, funciones y recursos. Las asociaciones de localidades tienen objetivos múltiples más allá de las antiguas obligaciones soberanas en la prestación de los servicios públicos con el fin de encarar la solución concreta de problemas con participación privada y social.

La descentralización puede visualizarse, bien desde la óptica fiscalista del estado, que reivindica el concepto de autonomías locales y regionales predeterminadas legalmente, o, bien desde la óptica del desarrollo social, que se sustenta en las autonomías comunitarias que están en la base de los movimientos sociales.

Es necesario, desde estas dos ópticas, analizar las situaciones en que se encuentra la gobernabilidad en sus distintas instancias, como gobiernos locales, regionales o nacional, pues, el ejercicio de la autonomía de unos puede limitar severamente la autonomía de otros.

La estrategia de descentralización se orienta en dos perspectivas: vista desde la regulación central que solo le interesa el problema fiscal, de competencias y funciones para mejorar la eficiencia administrativa con el fin de acercar al ciudadano, legitimar al gobierno y garantizar estabilidad política; $y$, des- de el ángulo de la emancipación social con plena asunción de autonomía comunitaria en la toma de decisiones, manejo de competencias y recursos, con el fin de garantizar desarrollo social y participación comunitaria.

Se esboza así, una doble concepción de descentralización que comporta grados de contradicción entre el ejercicio de la autonomía territorial, administrativa y fiscal, vista desde el gobierno central, y la autonomía comunitaria que ha trascendido los límites de las autonomías territoriales y se expresa en movilización social, en acciones colectivas y en movimientos sociales particulares más allá de las fronteras locales.

La privatización es una estrategia neoliberal que combina el desarrollo económico local, la representación de poder local y participación social en procesos de toma de decisiones. Detrás del traslado de competencias, funciones y recursos de la nación a las localidades para la política social y de prestación de servicios públicos, están los intereses de inversionistas privados.

Esta estrategia propone transformación de relaciones patrimoniales en verdaderas relaciones modernas dando primacía al capital financiero; y la búsqueda, aunque no se haya logrado, de la sustitución del clientelismo por un sistema político que encause la pluri-culturalidad social hacia una democracia participativa.

Descentralización y privatización han sido abordadas como estrategias centrales para mejorar la gobernabilidad 
neoliberal. La primera, acerca al Estado eficiente al ciudadano, quién legitima su accionar $y$, mediante la segunda, se descarga al estado de la función de producir bienes y servicios, dejando este rol a las empresas privadas que intervienen en los asuntos públicos.

"En las sociedades contemporáneas el vínculo entre gobernabilidad y democracia radica en el principio de la soberanía popular y en sus manifestaciones concretas, como son las elecciones periódicas y la participación ciudadana. En una democracia consolidada se cuenta con un buen número de recursos institucionales para prevenir $y$, en su caso, enfrentar los problemas de gobernabilidad"'.

Reforma Política Local. En el plano nacional, el gobierno se integra a la red del poder global y a la estructura de decisiones del gobierno mundial; el parlamento, cede su función legislativa a los organismos internacionales y a las empresas multinacionales, apoyadas en la globalización del derecho; $\mathrm{y}$, las decisiones judiciales son condicionadas por tribunales internacionales garantes de respeto a derechos humanos y al derecho internacional humanitario.

No obstante, los gobiernos neoliberales locales adquieren un poder de adaptación, a los factores reales del poder nacional y el gobierno mundial con base en su función de mediación del gobierno nacional entre grupos económicos dominantes y las empresas multinacionales, unos y otras, interesados y favorecidos por las ganancias propias del proceso de acumulación del capital global.

Bajo criterios neoliberales de dominio y apertura de mercado, la localidad cambia su estructura política con el fin de lograr: regulación fiscal, gestión de la descentralización territorial, administrativa y fiscal; privatización de las empresas públicas locales; garantizando participación política, conmutación del rol del ciudadano frente al consumidor, promoción de la justicia, la seguridad y del manejo del orden público local.

Reforma de la Gestión Local. El peso diferencial de cada uno de los elementos de la gestión local, se traducen en cambios sustanciales que van desde: la administración autoritaria a la nueva gestión pública; desde territorios cerrados y aislados a espacios públicos abiertos y virtuales; y, desde comunidades tradicionales a sociedades locales vinculadas en red.

La diversificación de funciones de organización y de gestión local promueven: el desarrollo sustentable, el fomento de la producción y el saneamiento básico; el desarrollo cultural, protección de la artesanía, de la industria cultural y el consumo masivo; aumento del tráfico mercantil y de flujos financieros en el espacio nacional/local.

Los nuevos compromisos políticos de la localidad respecto de la nación y

5 Camou, Antonio, Gobernabilidad y Democracia, Cuaderno de Divulgación de la Cultura Democrática, Instituto Federal Electoral. 
del mundo se traduce en el diseño de planes de desarrollo alrededor de políticas locales con fundamento en la planeación nacional y en orientaciones internacionales estratégicas.

Las colectividades territoriales han de asumir la planeación estratégica de la acción colectiva, que exige organización racional de la gestión local, en direcciones bien definidas en la política pública local: planeación económica, social y territorial

Primero, la planeación económica conlleva gestión sectorial de la producción con inversión externa, uso y gestión de transferencias de la nación y gestión de proyectos internacionales de protección del medio ambiente, es decir, el municipio debe gestionar el desarrollo económico con recursos propios y externos.

La promoción del desarrollo económico sustentable armoniza dos instancias esenciales: coordinación y ejecución de la política sectorial 1 con mejora de productividad y competitividad, conservación del medio ambiente; manejo adecuado de recursos naturales y regalías; transferencia de recursos y sistemas impositivos; política territorial y promoción de proyectos productivos empresariales locales, nacionales e internacionales, procurando saneamiento básico local y ambiental.

Este tipo de planeación no solo establece el balance entre ingreso y gasto local, sino que estimulan proyectos productivos y de protección del medio ambiente, al poner el acento en procesos de gestión que hagan viable el desarrollo sustentable local.
Segundo, planeación social con proyectos de cooperación, realizados con recursos nacionales e internacionales; de lucha contra la pobreza y de generación de fuentes de empleo; gestión de servicios de seguridad social con el concurso de distintas agencias públicas y privadas y participación clara en la gestión del desarrollo social. Igualmente, planeación cultural que implica gestión de redes nacionales e internacionales que promueven la industria cultural, el consumo y la construcción de una sociedad de masas, es decir, la nueva gestión del desarrollo cultural que asumen los gobiernos locales.

La planeación social orienta la acción y participación de distintas agencias oficiales, privadas, ONGS y organizaciones sociales en proyectos de desarrollo social con responsabilidades en la gestión del empleo y la seguridad social, gerenciando el desarrollo social.

También avanza la planeación cultural nacional e internacional al coordinar referenciales globales y nacionales sobre eliminación o limitación de la pobreza, creación de nuevas fuentes de empleo; promover la descentralización como proceso social que amplía y fortalece la democracia y garantiza ejecución de la política de seguridad social; generar empleo y la participación social.

La planeación demanda coherencia en tres instancias: una, en el complejo nacional e internacional, la política cultural se ocupa del papel del monopolio de los medios de comuni- 
cación, del acervo cultural, de la diferencia y homogeneidad cultural, de la etnicidad, raza y género ${ }^{6}$ dos, la cultura glocal se ocupa de la industria cultural, de la desigualdad, de la técnica y de la política cultural; de la cultura urbana y rural frente al ordenamiento territorial; y, tres, la cultura económica glocal con la impronta cultural que dejan turistas, inmigrantes, refugiados, exiliados, desplazados, trabajadores extranjeros y otras personas y grupos en constante movimiento?

Tercero, planeación territorial que comprende el reordenamiento territorial, los procesos de descentralización para el desarrollo urbano y rural, la armonización entre lo sectorial y lo territorial, la conformación de regiones e instancias subnacionales y supranacionales, y que deben gestionarse a nivel local.

Mediante la planeación del desarrollo territorial se busca gestionar la participación social en el proceso de planeación e implica la gestión agraria y del desarrollo urbano, desde el transporte y los servicios públicos, es decir la gestión local se ocupa de la promoción del desarrollo cultural.

Finalmente, debemos observar que si bien en este marco debería moverse el municipio moderno, en el caso colombiano, el municipio evoluciona lentamente y, por tanto, la hegemonía continúa en manos del gobierno central y su accionar público pierde eficacia e importancia en la resolución de los pro- blemas de los ciudadanos y de las poblaciones de comunidades que los componen.

Tesis 4: "La ambigüedad entre demandas del mercado y exigencias del modelo tradicional vigente, impone un conjunto de orientaciones y decisiones políticas del gobierno a la vida local, sin participación comunitaria y ciudadana, desvirtuando toda acción democrática".

Es decir, "A pesar de demandas globales de mediación territorial de los gobiernos locales y de producir ajustes en la política pública local, reforma política y de gestión, estas autoridades continúan ligadas a funciones soberanas sin mayor autonomía “

\section{Problemas de \\ Gobernabilidad Local}

Las dificultades de los gobiernos locales para solucionar adecuadamente la problemática local, en el marco del mercado, crean nuevos y a veces insalvables problemas de gobernabilidad local en el campo político, ingobernabilidad, ilegitimidad y autoritarismo.

En primer lugar, la ingobernabilidad Territorial. "La ausencia de descentralización territorial y el poder de los movimientos sociales, basados en la autonomía comunitaria, desbordan las autonomías de autoridades locales para ser asumidos por el gobierno nacional"

6 R. Robertson, Globalization, Londres, 1992

7 A. Appadurai, en U. Beck, Qué es la Globalización?, Paidós, Barcelona, 2000. 
Ni municipios, ni departamentos y regiones gozan de autonomía territorial y, por tanto, carecen de competencias, funciones y manejo autonómico de los recursos, situación que les resta capacidad de gobernabilidad, pues, solo administran funciones del Estado central, quedando inhabilitados para enfrentar la problemática comunitaria.

Por tanto, la resolución de los problemas de las comunidades que reivindican su autonomía, trasciende el ámbito local y regional, convirtiéndose en interlocutores válidos del gobierno central, lo que se manifiesta en los más variados convenios y compromisos pactados en el transcurso del tiempo con el gobierno nacional. Ante esta situación, gobiernos departamentales y municipales han perdido gobernabilidad por falta de autonomía territorial, competencias y recursos, lo que les impide tomar medidas y soluciones de la problemática comunitaria.

Las comunidades, acorde a sus autonomías, demandan de manera directa a las instituciones nacionales solución a sus problemas más sentidos, por considerar que ellas son de su competencia en materia de tierras, crédito, tecnología, medio ambiente, educación, salud, etc., trascendiendo de esta forma, fronteras municipales y departamentales, como también sus respectivas autonomías, limitadas a sus propias jurisdicciones, lo que les resta capacidad de gobierno.

En segundo lugar, esta situación de falta de capacidad de gobierno se traduce en la ilegitimidad de los proce- sos gubernamentales, es decir, la incredulidad de la comunidad en las alternativas de solución, lo que conduce a situaciones de anomia y hasta cierto punto de no obediencia a sus decisiones.

En tercer lugar, la falta de participación comunitaria en los destinos de las comunidad local por la profunda crisis del poder ciudadano y de las formas de representación poítica, es decir, la crisis de la democracia representativa. Al contrario sensu, se reivindica la democracia directa y los procesos de movilización social producen mayores grados de ilegitimidad de las distintas formas de gobierno.

Tesis 5: "Carencias de adecuadas estrategias de gobernabilidad-centralistas, descentralistas, privatistas-y emergencia de factores de gobernanza y presión ejercida por los movimientos sociales generan problemas de ingobernabilidad, ilegitimidad y autoritarismo"

\section{Gobernanza y Movimiento Social}

La noción de gobernanza sostiene que el logro de una adecuada gobernabilidad depende de una serie de acuerdos básicos entre las elites dirigentes, los grupos sociales estratégicos y una mayoría ciudadana, lo que conlleva desarrollo de una nueva cultura política de gobernabilidad democrática, es decir, un conjunto de ideas, principios y valores que intentan plasmar un equilibrio entre la responsabilidad ciudadana y la naturaleza, las posibilidades y los límites de la 
acción gubernamental en el marco de sociedades complejas ${ }^{8}$.

La gobernabilidad está asociada a la eficacia, a la legitimidad y a la estabilidad política del Estado para mantener la cohesión social necesaria para afrontar la modernización. Para Antonio Camou: estos tres componentes remiten a la tradición de: "razón de Estado" en términos del paradigma del gobierno eficaz; de la legitimidad del "buen gobierno"; y finalmente, a la "estabilidad" política.

La gobernanza busca mantener el equilibrio de la relación entre gobernantes y gobernados. Las demandas de los movimientos sociales sobre los gobiernos crecen y requieren de mayor capacidad de desempeño de éstos para aumentar el grado de gobernabilidad.

La ruptura del equilibrio podría llevar a la gobernabilidad autoritaria, cuando se impone la voluntad de gobierno sobre las demandas sociales o a una gobernabilidad democrática cuando las comunidades y los ciudadanos participan en toma de decisiones, en la solución de demandas sociales a fin de obtener buen gobierno.

La organización de los agentes políticos involucra la configuración de redes de política pública y de un proceso de jerarquización de actores que actúan desde las distintas instancias e intereses territoriales y comunales, a saber: local, regional, nacional; oficial, privado y social; y la participación de los individuos y comunidades en la vida pública local que aparece como el reconocimiento de la existencia de diversidad y pluralidad de la cultura local.

El movimiento social engendra poder que confronta con los gobiernos $\mathrm{y}$ autoridades en todos los niveles, locales, nacionales o globales, debilitando o apoyando las decisiones que estos toman en sus respectivas instancias.

"El poder de los movimientos se pone de manifiesto cuando los ciudadanos corrientes unen sus fuerzas para enfrentarse a las elites, a las autoridades y a sus antagonistas sociales. Estos movimientos atraen a la gente a la acción colectiva por medio de repertorios conocidos de enfrentamiento e introducción de innovaciones en torno a sus imágenes. En su base se encuentran las redes sociales y los símbolos culturales a través de los cuales se estructuran las relaciones sociales"

Tesis 6: "La incapacidad gubernamental para resolver este conjunto de problemas locales, pone en el centro de la controversia al enfoque social, tomando en cuenta el papel que juegan el conjunto de actores sociales (análisis de gobernanza) y el movimiento social alternativo".

\section{Globalización, Gobernabilidad y Movimientos Sociales}

"La acumulación capitalista en el modelo de mercado global, ha mostrado

\footnotetext{
8 Camou, Antonio, Op, Cit.

9 Tarrow, Sydney, El poder en Movimiento, Madrid, Alianza Editorial, 1997.
} 
ingobernabilidad mundial y nacional frente a la globalización de la riqueza y localización de la pobreza, a conflictos, guerras y movimientos sociales".

La globalización supone la estructuración de un nuevo orden mundial donde la capacidad de gobernabilidad tanto del gobierno mundial, rector de la política pública, como la del gobierno nacional, mediador de la misma, se haga manifiesta en la resolución de los problemas globales, evitando los movimientos sociales anti-globalización.

\section{Globalización y Nuevo Orden Mundial}

\section{Configuración del Estado} Transnacional y la de los Estados nacionales desarrollados con soberanía incluyente y la de los países en vías de desarrollo despojados de su soberanía excluyente en redes de poder, genera un tipo de gobernabilidad que distingue las decisiones del gobierno mundial frente a las ejecuciones de los gobiernos nacionales.

Los gobiernos mundial y nacionales en el marco del Modelo de Mercado son mediadores de la política Económica para la acumulación global del capital, las política social para la reproducción de la fuerza de trabajo, y, la política cultural para la universalización del consumo.

Los actores globales configurados como: gobierno mundial, Organismos Internacionales, Empresas transnacionales, gobiernos naciona- les, Movimientos sociales, Organizaciones no gubernamentales.

Tesis 7: "El nuevo orden mundial se construye con fundamento en la pérdida de soberanía de los Estados nacionales dependientes y su transferencia al gobierno mundial, a los organismos internacionales y a las empresas transnacionales".

\section{Gobernabilidad y Mediación Nacional}

La mediación de los gobiernos neoliberales en América Latina, en el marco del modelo de mercado cuyo objetivo es la acumulación de capital global, ha generado tres escenarios bien definidos en: política económica, reforma política y administración pública.

Mediación en Política Económica, reorientando la política financiera, productiva y comercial, en estos términos:

Primero, el sistema financiero buscando equilibrio entre ingresos y gastos con disciplina fiscal lo que implica disminución del gasto público, incremento de impuestos mediante reforma tributaria, exoneración a inversionistas y fijación de tasas de interés de mercado.

La libre fluidez del capital global, demanda estabilidad macro fiscal de los Estados menos desarrollados para acelerar las inversiones hacia estos, garantizar el retorno del capital al punto de partida con pago de deuda externa, reduciendo costos de inversión y facilitando la especulación financiera. 
Al efecto, se han venido estructurando un conjunto de instituciones financieras internacionales que comprenden ocho (8) organismos mundiales entre los que se cuentan, el FMI, el BM, el BIRF, 43 bolsas de valores, 61 organizaciones regionales y 146 bancos centrales emisores vinculados por red.

El sistema financiero se consolida como red de convenios entre la banca pública y privada, constituyendo el marco principal de la política financiera de los Estados Neoliberales y que articula los organismos internacionales, el Congreso de los EU, la Reserva Federal, altos cargos de la Administración y grupos de expertos.

En el ámbito financiero nacional e internacional, los grupos de interés dominantes se asocian en redes complejas que articulan un conjunto de inversionistas nacionales y foráneos interesados en la movilidad de flujos financieros entre productores, comerciantes y consumidores.

La hegemonía del capital financiero en los ultra neoliberales noventa, impone el Acuerdo Multilateral de Inversiones, AMI, que legaliza de facto los grandes oligopolios en los mercados; mientras la soberanía de los estados nacionales queda relegada y subordinada a las imposiciones de las empresas ${ }^{10}$.

Los objetivos centrales del AMI son: establecer un amplio marco multilateral para la inversión internacional con normas de alto nivel en materia de liberalización de regímenes de inversión y protección de inversiones y con procedimientos de solución de diferencias efectivos. Este acuerdo concede a las multinacionales nuevos y extensos poderes al mismo tiempo que niega a los gobiernos el derecho a controlar la inversión extranjera en sus países.

Segundo, el Sistema Productivo con la mundialización de la economía se ha traducido en cambios significativos en la organización productiva que explican el tránsito del modelo fordista hacia las distintas alternativas postfordistas, que dan respuesta a las necesidades del proceso de acumulación de capital y a los profundos avances en la tecnología, productividad y contratación salarial de la mano de obra.

La apertura de la inversión en la producción busca mejorar la productividad, la competencia y la flexibilización laboral que implica desempleo, bajos salarios, protección de la propiedad privada y privatización de las empresas estatales y de servicios públicos.

La configuración institucional de la producción mundial se da en torno a organismos y empresas transnacionales de EE.UU., de la Unión Europea y del Japón, que regulan sus avances, lo que traduce la consolidación de múltiples organizaciones empresariales, industriales, sindicales y sus proyecciones en los demás países del mundo.

La apertura a la inversión extranjera es la estrategia para liberar de res-

10 Cfr. Borón, Atilio A., Op., Cit. 
tricciones y de dificultades a la circulación del capital productivo, tanto en el país como fuera de él. Toda empresa, toda industria, todo país que quiera progresar tiene que proyectarse y al mismo tiempo "abrir sus fronteras" en el plano interno y a la competencia internacional.

Tercero, en el comercio nacional e internacional, las políticas y el accionar público y privado ha de orientarse a lograr el libre comercio, el proceso de desregulación del mercado y la libre competencia en un mercado, paradójicamente, monopolizado.

El modelo de comercio sometido de la OMC, del ALCA y del TLC, cobran expresión en los convenios y tratados de comercio firmados entre las empresas transnacionales y los países pobres con mediación de sus Estados y que tienen capacidad de determinar políticas comerciales, turísticas y de consumo

Los cambios organizacionales del comercio giran en torno a modelos y principios forjados en las más variadas instituciones del comercio mundial, integradas por el GATT, la Organización Mundial del Comercio, OMC, La Unión Europea, el TLC, el ALCA y, por supuesto, el Consenso de Washington.

La universalización del consumo, exige el acceso al libre comercio, aunque, como es de conocimiento general, se ha dado una previa repartición del comercio entre las empresas transnacionales, lo que ha servido de principio efectivo en orden a la superación del modelo tradicional de mercado interno para favorecer, en últimas, su expansión a escala mundial.
Mediación en la Reforma Política. Esta mediación demanda una Visión Integral del Nuevo Sistema Político. Este nuevo sistema político a diferencia del anterior por ser abierto tanto al interior como al exterior. Este sistema tiene como soporte el proceso de acumulación de capital en el plano mundial. Podemos distinguir cinco componentes esenciales del nuevo sistema político:

a. Poder económico que comprende la integración de los actores económicos (Estado Transnacional, Organismos Internacionales, Grupos Regionales, Empresas Transnacionales y Grupos Económicos Dominantes) frente a la soberanía del consumidor.

b. Poder Político del Buen Gobierno con capacidad de integrar instituciones nacionales de la antigua democracia representativa, en bloque monolítico: sistema electoral, partidos políticos y parlamento frente a la relativa autonomía de los ciudadanos.

c. Movimientos sociales globales que buscan integrar la justicia y equidad en torno al cumplimiento de los derechos humanos y, sobre todo del derecho internacional Humanitario con su estructuración en Organizaciones no Gubernamentales, ONGs.

d. Los Medios de Comunicación y de control político, atraviesan estas tres grandes dimensiones económica, política y social, desde la perspectiva del poder económico y con la misión de controlar las esferas política y social.

e. La Gestión Pública encargada del manejo de procesos económicos, 
financieros, productivos y comerciales; acciones gerenciales para el manejo del gasto público y control de los asuntos sociales. Este es el sentido, de la Nueva Administración Pública, NPA, que ha sido concebida como gerencia pública.

Mediación en la Reforma de la Administración Pública. "Las instituciones son las reglas del juego en una sociedad, o más formalmente, son las limitaciones ideadas por el hombre que dan forma a la interacción humana. Por consiguiente, estructuran incentivos en el intercambio humano sea político, social, o económico. El cambio institucional conforma el modo en que las sociedades evolucionan a lo largo del tiempo, por lo cual es la clave para entender el cambio histórico" (North, 1993) $)^{11}$.

A comienzos de la década del noventa, en América Latina y en Colombia se dio inicio a una serie de reformas de carácter estructural. Se asumió un nuevo modelo de desarrollo económico basado en la internacionalización y apertura de la economía, para lo cual era necesaria la implantación de un conjunto de reformas de tipo estructu$\mathrm{ral}^{12}$.

La adecuación de las entidades del Estado Central a las exigencias del $\mathrm{Mo}$ delo Neoliberal exigió una reforma institucional que suprimió funciones, eliminó algunas entidades, en especial, las dedicadas al control de cambios y permisos de inversión extranjera; reforzó labores reguladoras, creó organismos especializados y se hizo posible la intervención de agentes privados en la prestación de los servicios que antes monopolizaba el Estado.

El programa de apertura económica de 1990 incluyó, entre otros aspectos, la reorganización de las instituciones relacionadas con el sector externo, liberalización del régimen cambiario, eliminación del mecanismo de licencia previa de las importaciones y una rebaja arancelaria manifiesta en la reducción de la protección hasta en una tercera parte entre 1989 y 1993. También se dio impulso a los procesos de integración económica con los países vecinos ${ }^{13}$.

Tesis 8: "Los gobiernos de los Estados nacionales se convierten en mediadores de la politica pública, de la reforma politica y de la administración pública del capitalismo mundial, ampliando la brecha entre riqueza y pobreza con violación reiterada del DIH".

\section{Problemas Globales y Movimientos Anti- Globalización}

Los problemas del mundo se expresan como: globalización de la rique-

11 North, 1993, citado por Garay S., Luís Jorge, Banco de la República, Colombia: Estructura Industrial e Internacionalización, Capítulo 2, institucionalidad y política industrial, 1967-1996

12 Garay S., Luís Jorge, Banco de la República, Op., Cit.

13 Garay S., Luís Jorge, Banco de la República, Op., Cit. 
za y localización de la pobreza produciendo conflictos y guerras con la violación reiterada de los derechos humanos y del derecho internacional humanitario.

Movimientos sociales globales que buscan integrar la justicia y equidad en torno al cumplimiento de los derechos humanos y, sobre todo del derecho internacional Humanitario con su estructuración en Organizaciones no Gubernamentales, ONGs.

"Si salimos del mundo de la política formal y miramos a la sociedad, observamos la fuerza creciente, en la calle y en la opinión pública, del movimiento antiglobalización (o en favor de una globalización alternativa, según las tendencias que coexisten en el movimiento) "'14.

Los activistas antiglobalización exigen una sociedad más justa, el control del poder ilimitado de las multinacionales, democratización de las instituciones económicas mundiales y distribución más equitativa de la riqueza. Sus enemigos principales son las multinacionales y las grandes organizaciones económicas y políticas internacionales, fundamentalmente el Banco Mundial (BM), el Fondo Monetario Internacional (FMI) y la Organización Mundial del Comercio, OMC.

El Banco Mundial y el Fondo Monetario Internacional son, para los grupos antiglobalización, los responsables de la asfixiante situación en la que se encuentran la mayor parte de los países pobres, incapaces de afrontar la deuda que en muchos casos supera su PIB (Producto Interior Bruto).

Tesis 9: "La globalización de la riqueza y localización de la pobreza, expresas en injusticia, inequidad y exclusión social, generan procesos de emancipación social, poniendo en primer plano a los movimientos alternativos antiglobalización".

\section{Bibliografía:}

Archila, Mauricio y Pardo, Mauricio. Movimientos Sociales, Estado y Democracia en Colombia: CES/UN/ICANH, 2001.

Beck, ulrich, ¿qué es la globalización?, paidós, barcelona, españa, 2000

Boiero, Marta y Estrada, Gabriela, II Congreso Argentino de Administración Pública 2003

Brugé, Quim y Gomá, Ricard, Gobiernos locales y politicas públicas, ariel ciencia política, barcelona, 1998 .

Camou, Antonio, Gobernabilidad y democracia, Cuaderno de divulgación de la cultura democrática, instituto federal electoral.

Fescol, compiladores (Alejandro Becker, Carolina Chica y Miguel Eduardo Cárdenas), Ordenamiento territorial, reivindicación de la descentralización para el desarrollo, grafivisión editores ltda., bogotá, d.c., 2003.

IUÉD (suiza) y PARCOMÚN (Colombia), El Futuro de la Descentralización: experiencias de quince años y perspectivas, IV Encuentro Colombia hacia la paz, Ginebra, Suiza, 2002

14 Castells, Manuel, La Crisis de lo Político, Nuevos Rumbos, Julio de 2002. 
Laraña, Enrique, La Construcción de los Movimientos Sociales, Alianza Editorial, 1999.

Muller Pierre. Surel Yves. L'analyse cognitive des Politiques Publiques: vers une sociologie politique de l'action publique. Revue française des sciences politique. Vol. $50 \mathrm{n} 2$ avril 2000.

ONU, Cumbre del Milenio, Declaración del Milenio de Naciones Unidas, Nueva York, Septiembre de 2000.

PNUD. (2003) La democracia en América Latina. Hacia una democracia de ciudadanas y ciudadanos.

Prats Joan. Gobernabilidad Democrática para el Desarrollo Humano. Marco conceptual y analítico.

Rivas, Arturo, Metodología para el Estudio de los Movimientos Sociales, Ediciones Trota, España, 1998

Rivas, Nelly (Coordinadora técnica PacChocó), Informe Técnico Proyecto Autonomía Comunitaria, IIAP y UTR., 2004.

Robertson, Roland, Globalization: Social Theory and Global Culture, Londres, Sage, 1992.

Tarrow, Sydney, El Poder en Movimiento, Acción Colectiva y Politicas, Madrid, Alianza Editorial, 1997. 